\title{
Smart monitoring system of composite plates for structural health monitoring using electromechanical impedance approach
}

\author{
Jayachitra Tanabalou, Rashmi Priyadarshini \\ Department of Electrical Electronics and Communication Engineering, Sharda University, Uttar Pradesh, India
}

\begin{tabular}{|c|c|}
\hline Article Info & ABSTRACT \\
\hline Article history: & \multirow{11}{*}{$\begin{array}{l}\text { The damage detection in structural health monitoring was performed in glass } \\
\text { fiber composite plates and carbon nanotude composite plates. } \\
\text { Electromechanical Impedance technique was used for identification of } \\
\text { damage using lead zirconate titanate patches. Impact on composite structure } \\
\text { was created artificially by drilling a hole in composite structures. Bolt } \\
\text { stiffnesss were detected by loosening of bolts and nuts in the composite } \\
\text { structures. Corrosion occurs due to the aging and change of environmental } \\
\text { conditions. The novelty in this paper is the use of corroded bolts in } \\
\text { composite structures and identified the effects of corrosion and compared } \\
\text { the output signatures with potentiostat. In this paper common deformation } \\
\text { detection in composite plates, measurement of bolt stiffness and effects of } \\
\text { corrosion has been performed. Measurement of Impedance at different } \\
\text { frequencies were normalized with the undamaged composite structures and } \\
\text { considered as the reference signatures. These results have been analyzed and } \\
\text { verified with the output from potentiostat. }\end{array}$} \\
\hline Pocoived I & \\
\hline Received Jun 30, & \\
\hline & \\
\hline Accepted Dec 28, 2021 & \\
\hline Keywords: & \\
\hline Composite plates & \\
\hline Damage detection & \\
\hline Electromechanical Impedance & \\
\hline Potentiostat & \\
\hline Structural health monitoring & \\
\hline
\end{tabular}

This is an open access article under the CC BY-SA license.

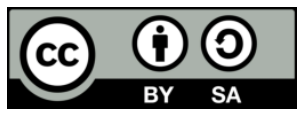

\section{Corresponding Author:}

Jayachitra Tanabalou

Departement of Electrical Electronics and Communication Engineering, Sharda University

Knowledge Park II, Greater Noida, Uttar Pradesh-201310, India

Email: jayachitra.kishor@sharda.ac.in

\section{INTRODUCTION}

Structural health monitoring (SHM) is the most promising tool for the protection and reliability of the civil, aerospace and mechanical structures [1]. Application of composite materials in these structures are rising due to their flexibility, strength and less weight. Damage may proceed at the construction side lifetime of the material or environment conditions [2]. For testing the damage in composite structures always non destructive method is used. The non destructive method used for measurement of damage in composite materials are classified as contact and noncontact methods. Testing using ultrasonic, eddy current and electromagnetic waves comes under contact methods [3]-[5]. In these methods, sensors are attached to the structure to get the data regarding the damage. Non contact methods include infrared, radiography and holography where the physical connection between sensor and the structure are not required [6]-[9]. Electromechanical impedance method (EMI) is the most promising contact method to detect the local damages at high sensitivity [10]. In this method, piezo electric transducer is used wich has piezoelectric property. The piezoelectric materials provide piezoelectric property which combines both the electrical and mechanical impedance of the structure. The damage in the structure results in the variations in physical characteristic like mass and stiffness which will change the mechanical impedance of structure. The damage can be detected from the electrical impedance of the piezo sensor [11].

The first EMI model was proposed by Liang et al. [12] using piezo sensors. The EMI technique was employed in concrete, bridges and pipeline structures to detect the damage effectively [13]-[17]. EMI 
techniques were employed in realtime application in the joints of bridges [13]. At various loading conditions, the monitoring of concrete bridge was performed using piezo patches [14]. Cracks in composite plates are identified using embedded piezo sensors on energy variation using wavelet analysis [18], [19]. Detection of damage in the composite at various locations are performed using Finite element analysis [20]. Several methods of attachment employed on glass fiber composites and detection of damage was performed and verified by finite element method [21]. The change in frequency and phase indicates the detection of damage but theoretically there would be no change in resonant frequency [22], [23]. The composite properties were reviewed for the applications in biomedical field [24].

Croitoru et al. introduced several damages like environmental condition, severe impacts and different loads in composite structure [25]. Composite structures with smart materials produce a noticable change in electrical conductivity when stress or strain was applied to the structure. The change in electrical parameters indicates the presence of damage [26]. Composite plate made of glass friber polymer was used for the damage detection using EMI technique. Impedance Analyzer was used to measure the impedance. Damage was induced into the strucrure using the projectile of energy $30 \mathrm{~J}$ [27]. Bonding of sensors with the structure also affects the detection of damage [28]. Impedance chip was used to identify the damage in the composite structures by proper calibration. The validation of calibration in the impedance chip was performed with impedance analyzer [29].

\section{METHODOLOGY}

Damage detection of glass composite plate and carbon nanotube composite was performed using EMI measurement. Composite plate of size $(200 \times 100 \times 3) \mathrm{mm}^{3}$ was chosen for analysis. Lead zirconate titanate transducer (PZT) was surface mounted on the plate using epoxy resin. The model was analyzed without damage and considered as the reference. Several damages inculcated in the composite plate for the measurement of EMI. AD5933 was used for measurement of impedance sweeping at the frequency level from $30 \mathrm{KHz}$ to $100 \mathrm{KHz}$. First, the damage hole of radius $20 \mathrm{~mm}$ was drilled, and impedance was measured. Second, bolts were used to connect a small composite plate of size $(100 \times 50 \times 3) \mathrm{mm}^{3}$. Due to the external aspects of the environment, corrosion takes place and hence corroded bolts were taken into consideration. Third the corroded bolts were used and impedance was measured at every step of thread loosening in the bolt. For every stage, the measured impedance signature was stored. The impedance signatures were processed and plotted in Matlab or Microsoft Excel. The impedance signatures were noted in potentiostat in the same model and stored. The signatures from the impedance chip were verified from the potentiostat impedance signatures.

Figures 1 to 4 represents the experimental setup of glass fiber and carbon nanotube composite plate for measurement of impedance using AD5933 and potentiostat. Figure 1 shows the glass composite plate with a drilled hole and the impedance measured at piezo sensor using AD5933. The impedance data was obtained by the user defined software of AD5933.

Figure 2 specifies the interface of glass composite plate with the carbon nano tube composite plate using new bolts. The variation in the bolt position indicates the presence of damage in the structure. The bolt might get corroded in due course of time. The corroded bolts are also experimented in composite structure as shown in Figure 3. Figure 4 shows the experimeantation set up of the impedance measurement in composite plates using potentiostat. The data obtained from the potentiostat was verified with the impedance measurement by AD5933.

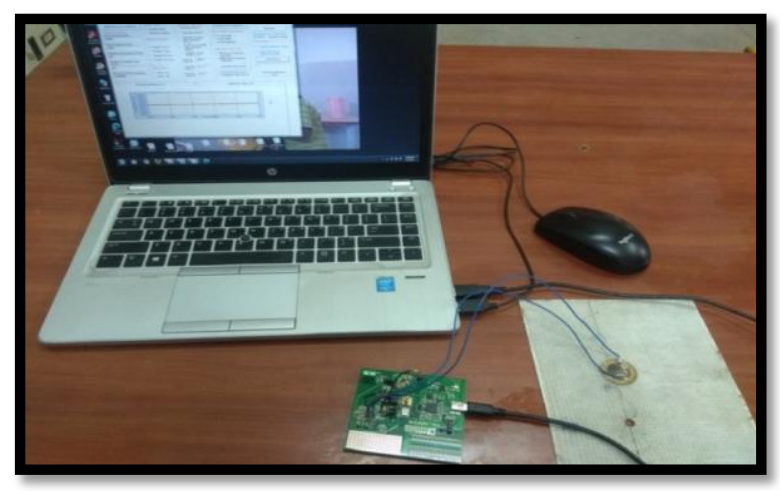

Figure 1. Impedance measurement of glass composite plate with a hole using AD5933 


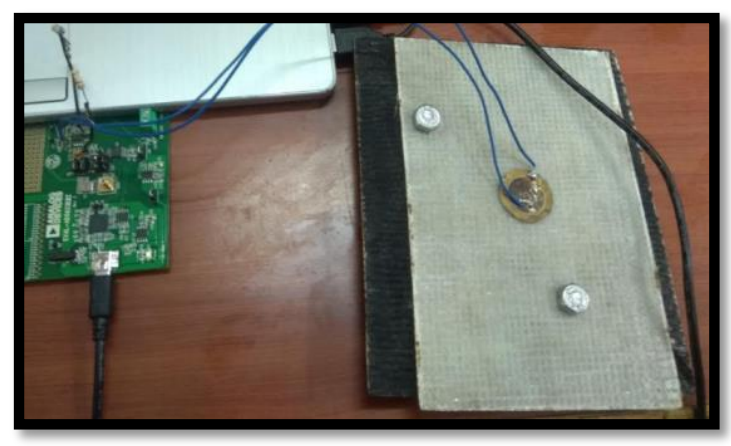

Figure 2. Impedance measurement of carbon nanotube with attached new bolt

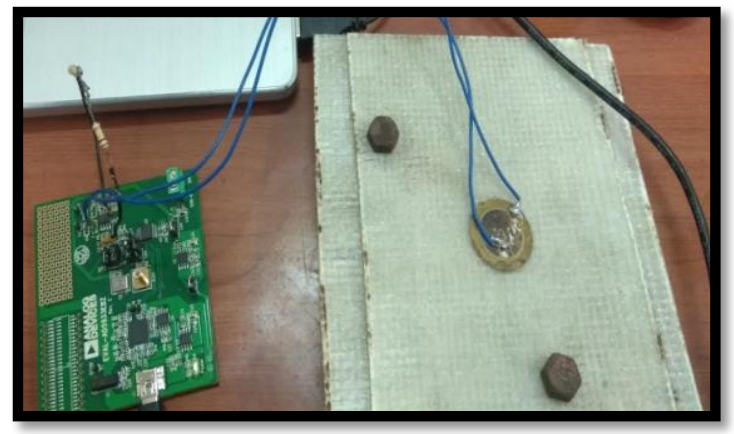

Figure 3. Impedance measurement of glass composite plate with corroded bolt

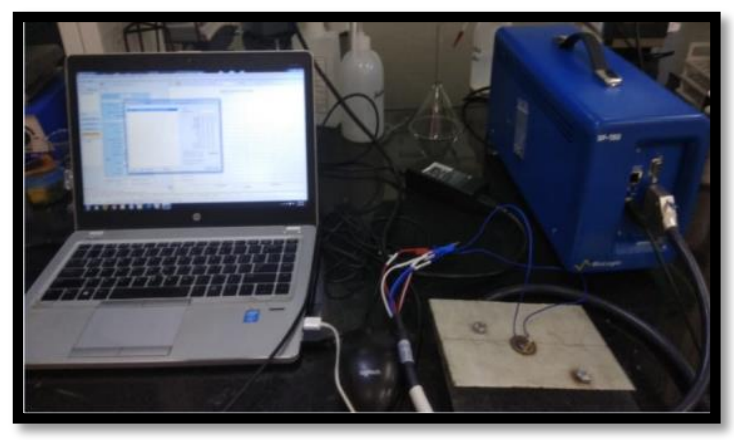

Figure 4. Impedance measurement of composite plate using potentiostat

\section{RESULTS AND DISCUSSION}

In this proposed method, two composite plate, glass fiber and carbon nanotube were used. Damage is created artificially in this experiment by drilling a hole in the composite plates. Impedance signatures were measured with undamaged and damaged position. Figures 5 and 6 show the impedance signatures obtained between undamaged and two different types of damage in glass fiber composite and carbon nanotube composite plate. The inclusions of two holes using driller are the damages introduced in the composite structures. The impedance increases clearly when subjected to damage. The impedance peak was high at $50 \mathrm{KHz}$ which is resonant frequency. The resonant frequency of the undamaged system is the same as the damaged system but the amplitude varies. The impedance value increases as the damage level in the composite plate increases. The impedance increases from $199.7 \mathrm{~K} \Omega$ to $200.5 \mathrm{~K} \Omega$ which shows the presence of damage on the structure.

Bolts are used to attach the composite plates with a small glass fiber composite. Figures 7 and 8 show the impedance signatures of new bolt for connection of glass fiber and carbon nanotube composite plate. The threads in the bolt are varied to measure the impedance for damage detection in the composite plates. The results clearly indicate the variations in the pattern when new bolt is unfastened at every step. The 
impedance increases as the damage level increases. The impedance peak is at $40 \mathrm{KHz}$ and $50 \mathrm{KHz}$. The impedance increases from $199.7 \mathrm{~K} \Omega$ to $200 \mathrm{~K} \Omega$ which shows the presence of damage due to loosening of bolts at the level 1 in carbon fiber composite plates. The impedance varies from $199.7 \mathrm{~K} \Omega$ to $200.3 \mathrm{~K} \Omega$ which detects the damage due to loosening of bolts at the level 2 in carbon fiber composite plates. The impedance increases from $199.7 \mathrm{~K} \Omega$ to $200.3 \mathrm{~K} \Omega$ which shows the presence of damage due to loosening of bolts at the level 2 in carbon nanotube composite plates. Due the the high flexible strength of carbon nanotube, loosening at the first stage has no changes in the impedance signatures.

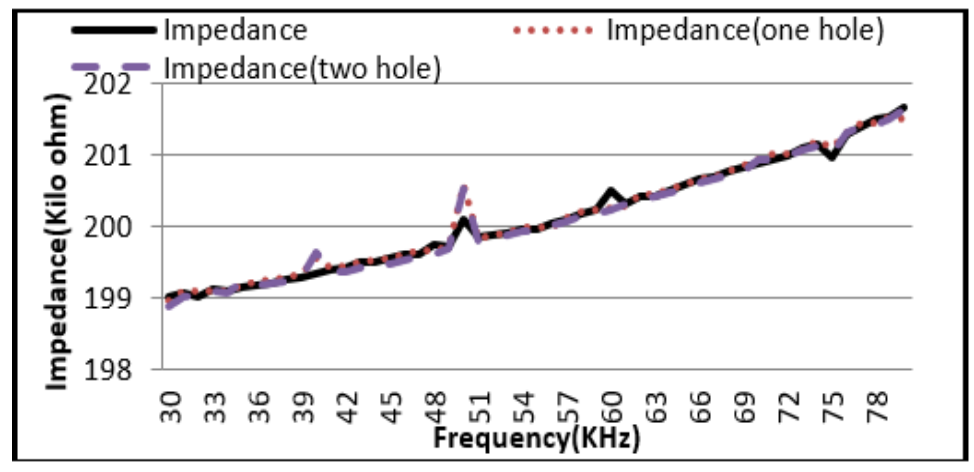

Figure 5. Impedance signature of glass fiber composite at different frequency with and without hole

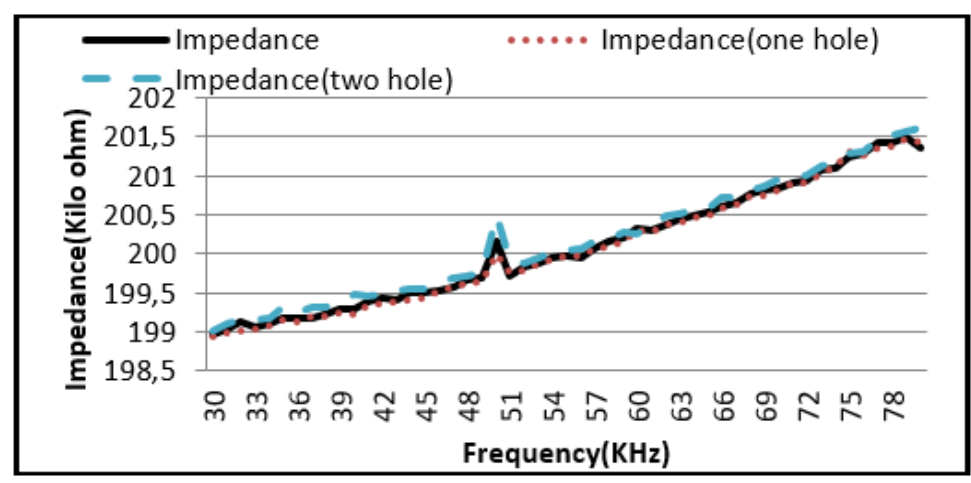

Figure 6. Impedance signature of carbon nanotube composite at different frequency with and without hole

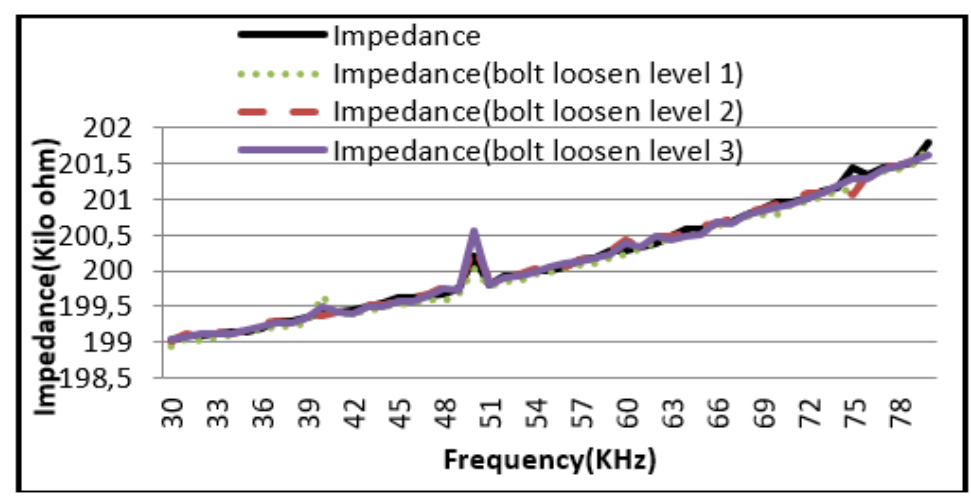

Figure 7. Impedance signature of glass fiber composite at different frequency with loosening of bolts

Due to varying environment conditions, there are high chances of corrosion to occur in bolts so the experiment was extended by using corroded bolts. Figures 9 and 10 show the impedance signatures of using 
corroded bolts in composite glass fiber and carbon nanotube composite. The impedance value increases as the bolts are interchanged with the corroded bolts. The impedance peak occurs at $40 \mathrm{KHz}$ and $50 \mathrm{KHz}$.

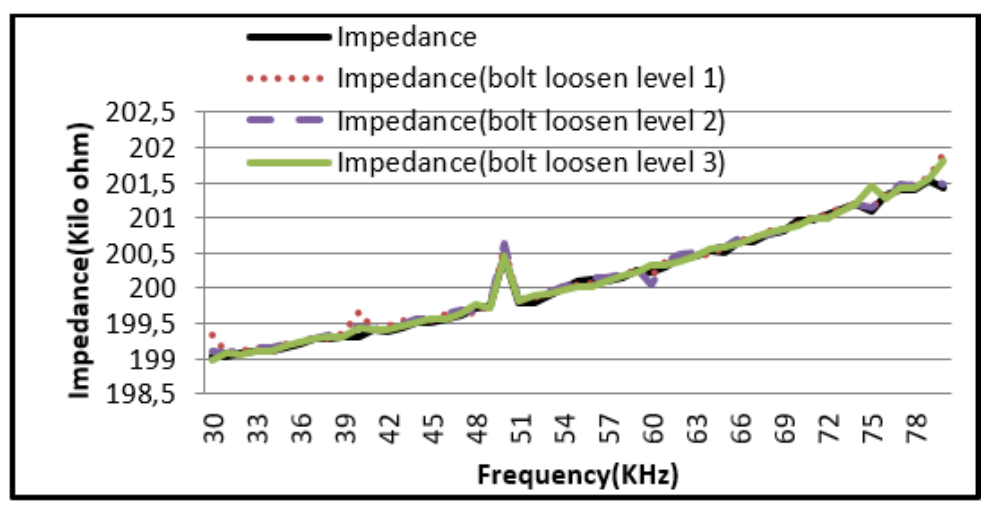

Figure 8. Impedance signature of carbon nanotube composite at different frequency with loosening of bolts

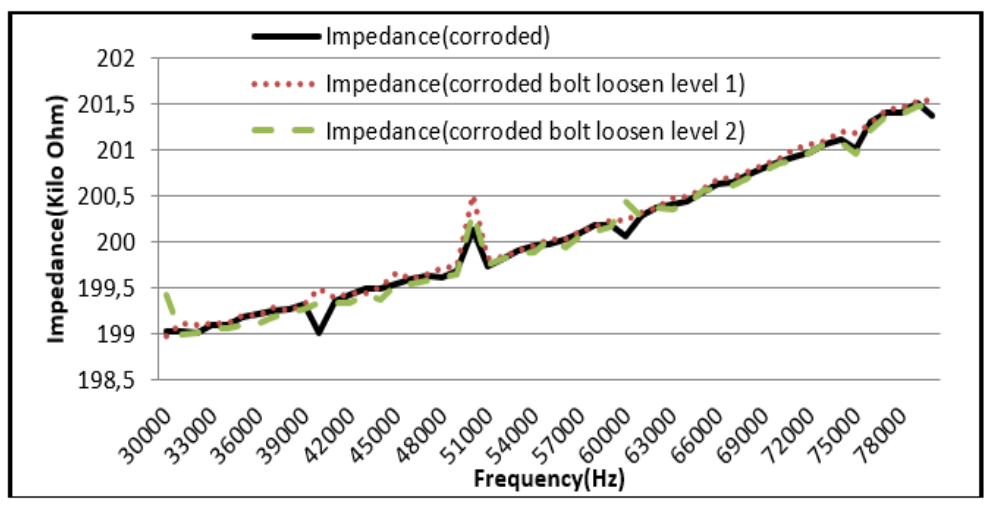

Figure 9. Impedance signature of glass fiber composite at different frequency with loosening of corroded bolt

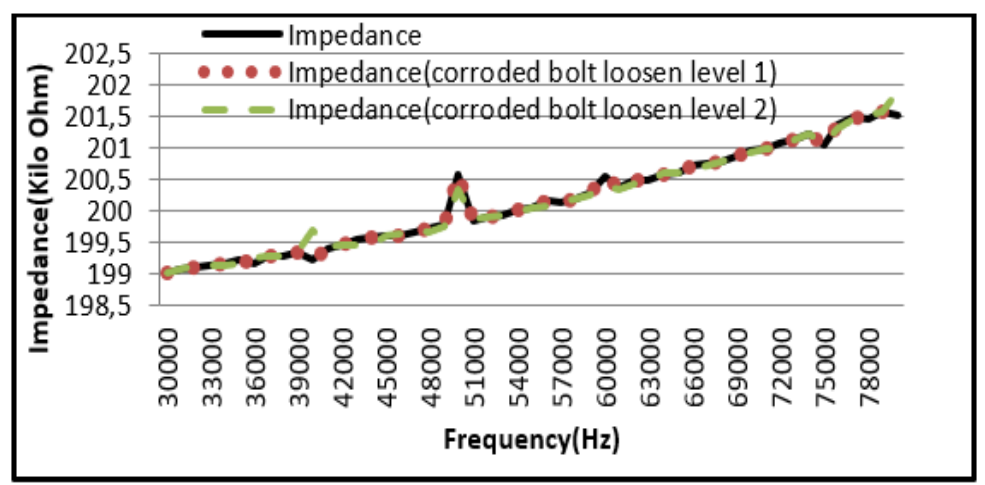

Figure 10. Impedance signature of carbon nanotube composite at different frequency with loosening of corroded bolt

The same experimental set up was used for verification by potentiostat. From the Figures 11 and 12 the impedance peak remains the same in potentiostat and impedance chip which occurs at $50 \mathrm{KHz}$. The amplitude of impedance increases as the damage level increases. The multiple peaks of impedance signatures at different frequency level have a good agreement with the conventional impedance measurement. 


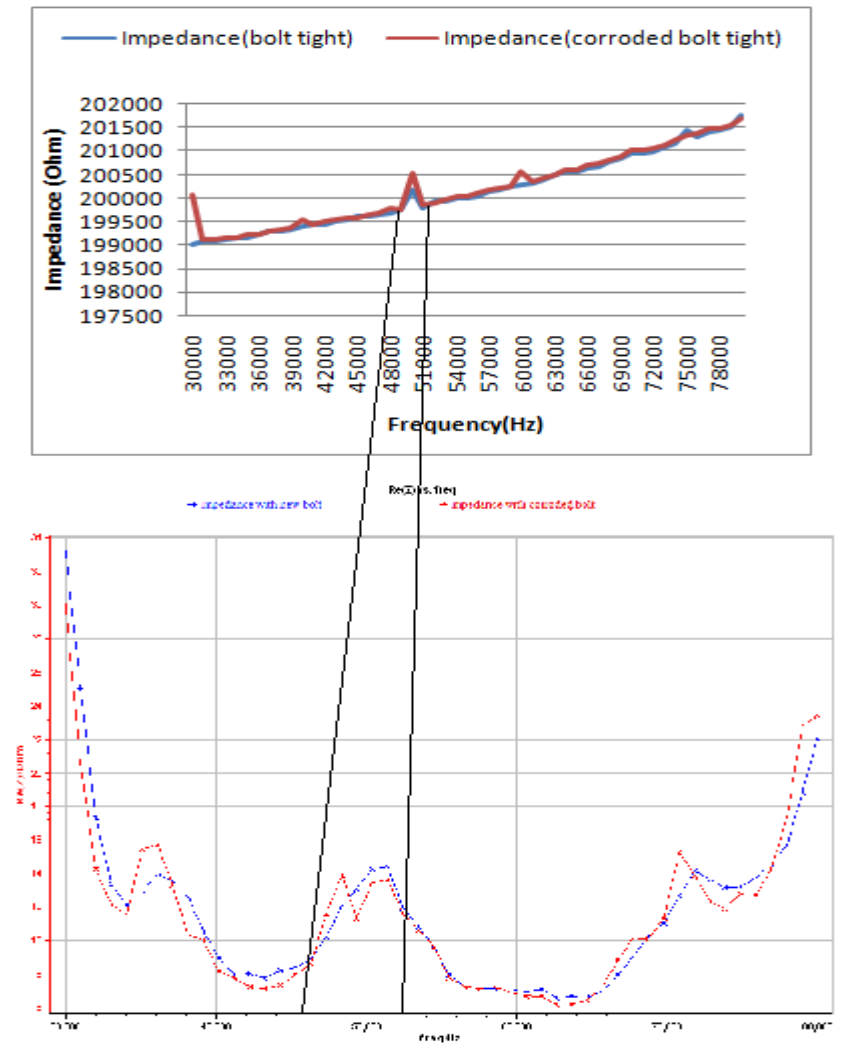

Figure 11. Comparison of Impedance signature from AD5933 and poteniostat at different frequency of glass fiber composite plate

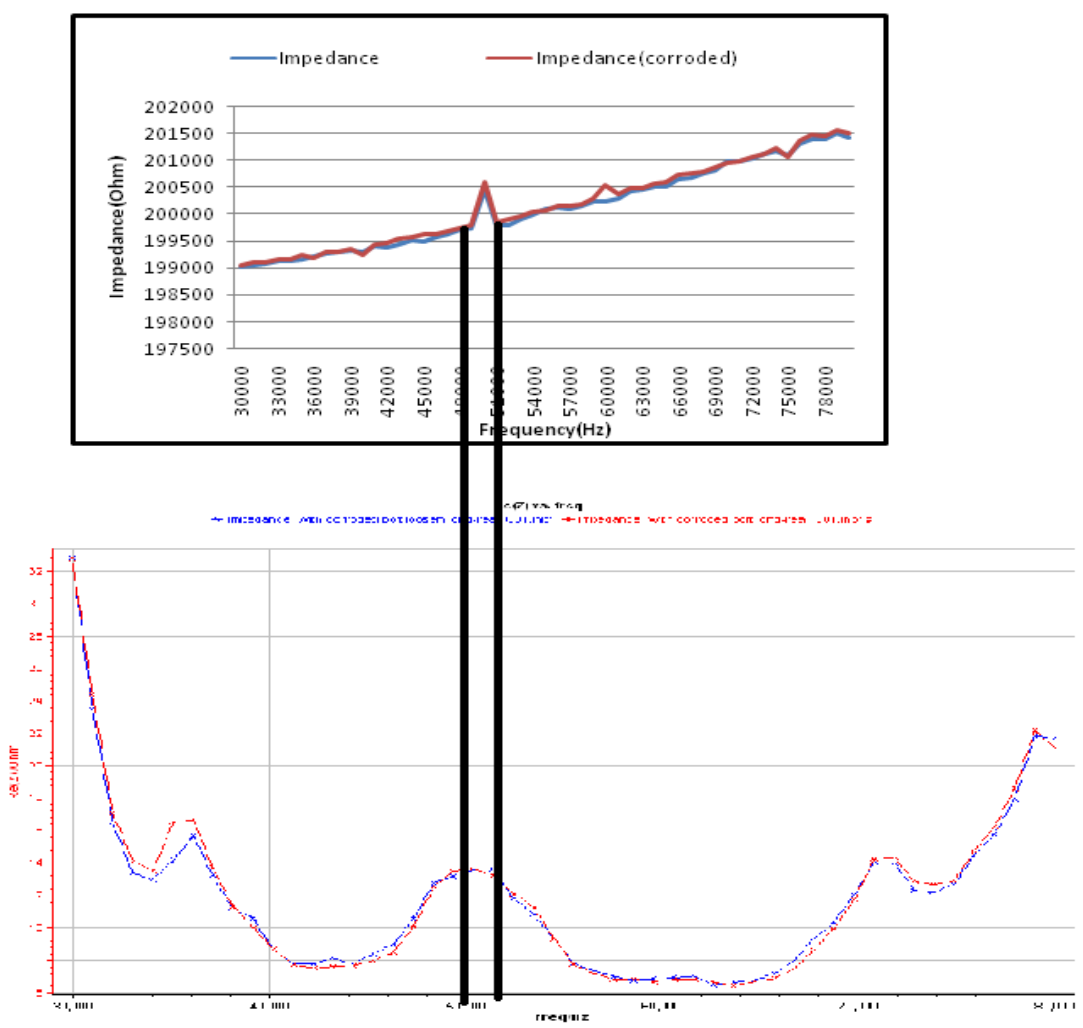

Figure 12. Comparison of Impedance signature from AD5933 and poteniostat at different frequency of carbon nano tube composite plate 


\section{CONCLUSION}

In this research, the damage detection of composite plate has been performed using EMI technique. Composite glass fiber and carbon nanotube composite plate with surface bonded PZT have been utilized for this study. The damage was identified by developing the holes onto the structures. Then the bolt stiffness was checked by loosening the bolts in the structure. Finally, the corrosion effects were detected in composite materials. The damage was detected by the increase in impedance value at resonant frequency. A novel comparison approach was performed. The signatures of impedance chip were validated with potentiostat instrument. The results of impedance chip indicate that the impedance signatures at different level of damage have a good agreement with the signatures obtained from potentiostat. The work of impedance chip was found to be accurate with the conventional measurements.

\section{REFERENCES}

[1] S. Park, C.-B. Yun, Y. Roh, and J.-J. Lee, "PZT-based active damage detection techniques for steel bridge components," Smart Materials and Structures, vol. 15, no. 4, pp. 957-966, 2006, doi: 10.1088/0964-1726/15/4/009.

[2] T. Jollivet, C. Peyrac, and F. Lefebvre, "Damage of composite materials," Procedia Eng., vol. 66, pp. 746-758, 2013, doi: 10.1016/j.proeng.2013.12.128.

[3] F. Aymerich and S. Meili, "Ultrasonic evaluation of matrix damage in impacted composite laminates," Compos. Part B-Eng., vol. 31, no. 1, pp. 1-6, 2000, doi: 10.1016/s1359-8368(99)00067-0.

[4] M. P. De Goeje and K. E. D Wapenaar, "Non-destructive inspection of carbon fibre-reinforced plastics using eddy current methods," Composites, vol. 23, pp.147-157, 1992, doi: 10.1016/0010-4361(92)90435-w.

[5] I. G Scott and C. M Scola, "A review of non-destructive testing of composite materials," NDT Int., vol. 15, pp.75-86, 1982, doi: 10.1016/0308-9126(82)90001-3.

[6] N. P Avdelidis and A. Moropoulou, "Applications of infrared thermography for the investigation of historic structures," J. Cult. Herit., vol. 5, no. 1, pp. 119-127, 2004, doi: 10.1016/j.culher.2003.07.002.

[7] P. Cloetens, M. P. Salome, J. Y Buffiere, G. Pelix, J. Baruchel, F. Peyrin, and M. Schlenker, "Observation of microstructure and damage in materials by phase sensitive radiography and tomography," J. Appl. Phys., vol. 81, no. 9, pp. 5878-5886, 1997, doi: $10.1063 / 1.364374$

[8] D. Wu, Th. Zweschper, A. Salerno, and G. Busse., "Lock-in thermography for nondestructive evaluation of aerospace structures," NDT. Net, vol. 3, no. 9, 1998, doi: 10.1016/S0035-3159(98)80047-0.

[9] J. A Dos Santo, H. M. R. Lopes, M. Vaz, C. M Mota Soares, C. A Mota Soares, and M. J. M De Freitas, "Damage localization in laminated composite plates using mode shapes measured by pulsed TV holography," Compos. Struct., vol. 76, pp. 272-281, 2006, doi: 10.1016/j.compstruct.2006.06.

[10] H. Song, H. J Lim, and H. Sohn, "Electromechanical impedance measurement from large structures using a dual piezoelectric transducer," J. Sound Vib., vol. 332, no. 25 pp. 6580-6595, 2013, doi: 10.1016/j.jsv.2013.07.023.

[11] D. Xu, X. Cheng, S. Huang, and M. Jiang, "Identifying technology for structural damage based on the impedance analysis of piezoelectric sensor," Constr. Build. Mater., vol. 24, no. 12, pp. 2522-2527, 2010, doi: 10.1016/j.conbuildmat.2010.06.004.

[12] C. Liang, F. P. Sun, and C. A. Rogers, "Coupled electro-mechanical analysis of adaptive material systems-Determination of the actuator power consumption and system energy transfer,” J. Intell. Mat. Syst. Struct., vol. 8, no. 4, pp. 335-343, 1997, doi: $10.1177 / 1045389 \times 9700800406$.

[13] J. W. Ayres, F. Lalande, Z. Chaudhry, and C. Rogers., "Qualitative impedance-based health monitoring of civil infrastructures," Smart Materials and Structures, vol. 7, no. 5, pp. 599-605, 1998, doi: 10.1088/0964-1726/7/5/004.

[14] C. K. Soh, K. Tseng, and S. Bhalla, "Performance of smart piezoceramic patches in health monitoring of a RC bridge," Smart Materials and Structures, vol. 9, no. 4, pp. 533-542, 2000, doi: 10.1088/0964-1726/9/4/317.

[15] G. Park, H. H. Cudney, and D. J. Inman, "Impedance-based health monitoring of civil structural components," Journal of Infrastructure Systems, vol. 6, pp. 153-160, 2000, doi: 10.1061/(ASCE)1076-0342(2000)6:4(153).

[16] G. Park, H. H. Cudney, and D. J. Inman, "Feasibility of using impedance-based damage assessment for pipeline structures," Earthquake Engineering and Structural Dynamics, vol. 30, no. 10, pp. 1463-1474, 2001, doi: 10.1002/eqe.72.

[17] G. Park, D. E. Muntges, and D. J. Inman, "Self-monitoring and self-healing jointed structures," Key Engineering Materials, pp. 75-84, 2001, doi: 10.4028/www.scientific.net/KEM.204-205.75.

[18] Y. J. Yan and L. H. Yam, "Online detection of crack damage in composite plates using embedded piezoelectric actuators/sensors and wavelet analysis," Compos. Struct., vol. 58, no. 1, pp. 29-38, 2002, doi: 10.1016/s0263-8223(02)00043-0.

[19] Y. J. Yan, L. H. Yam, Y. Y. Li, and W. O. Wong, "Detection of crack damage in composite laminates using smart material and wavelet analysis," Proc. 8th Int. Conf. on 'Sound and Vibration, 2001, vol. 7, pp. 2349-2356.

[20] D. D. Niu, C. Li, and Y. Tie, "Numerical analysis of the damage detection in composite plates based on the electromechanical impedance method," Materials Research Innovations, vol. 19, pp. 5-10, 2015, doi: 10.1179/1432891715z.0000000002075.

[21] R. Tawie, H. B. Park, J. Baek, and W. S. Na, "Damage Detection Performance of the Electromechanical Impedance (EMI) Technique with Various Attachment Methods on Glass Fibre Composite Plates," Sensors, vol. 19, no. 5, pp. 1-13, 2019, doi: $10.3390 / \mathrm{s} 19051000$.

[22] R. Dugani, "Novel transducer for characterization of low-impedance materials," Key Engineering Materials, vol. 558, pp. 435558, 2013, doi: 10.4028/www.scientific.net/kem.558.435.

[23] R. Dugani, "Novel nondestructive evaluation transducer for imaging of low-impedance targets," Journal of Intelligent Material Systems and Structures, vol. 26, no. 3, pp. 340-351, 2015, doi: 10.1177/1045389X14525493.

[24] P. R. Monich, B. Henriques, and A. P. N. de Oliviera, "Mechanical and biological behavior of biomedical PEEK matrix composites: A focused review," Materials Letters, vol. 185, pp. 593-597, 2016, doi: 10.1016/j.matlet.2016.09.005.

[25] E. I. Croitru et al., "Impact testing on composite panels of fiberglass, carbon and Kevlar-carbon: a comparison and validation study," Materiale Plastice, vol. 54, pp. 700-707, 2017, doi: 10.37358/MP.17.4.4928.

[26] P. N. Reddy, B. V. Kavyateja, and B. B. Jindal, "Structural Health Monitoring methods, dispersion of fibers, micro and macro structural properties, sensing and mechanical properties of self sensing concrete - A review," Structural Concrete, pp. 1-13, 2020, doi: $10.1002 /$ suco.202000337. 
[27] P. H Malinowski, T. Wandowski, and S. K singh., "Employing principal component analysis for assessment of damage in GFRP composites using electromechanical impedance," Composite Structures, vol. 266, no. 2, 11380, 2021, doi: 10.1016/j.compstruct.2021.113.

[28] S. Moharana, "Investigation of a contimuum shear lag model as an indicator for the damage detection in Piezo-Elasto dynamic structure," Journal of Vibration Engineering \& Technologies, vol. 9, pp. 1755-1768, 2021, doi: 10.1007/s42417-021-00326-6.

[29] T. Wandowski, P. H. Malinowski, and W. M. Ostachowicz, "Improving the EMI based damage detection in composites by the calibration of AD5933 chip," Measurement, vol. 171, p. 108806, 2021, doi: 10.1016/j.measurement.2020.108806.

\section{BIOGRAPHIES OF AUTHORS}
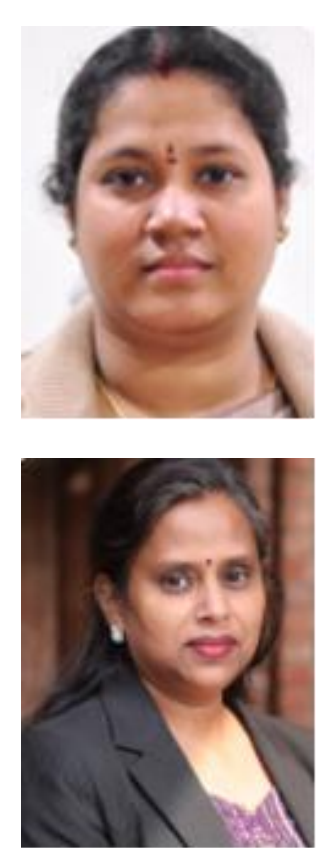

Jayachitra Tanabalou (D) SC P is currently pursuing her PhD in Department of Electrical and Electronics Engineering, Sharda University, Greater Noida, Uttar Pradesh, India. Her research interests are Wireless Sensor Network, Microstrip antennas and IoT. She can be contacted at email: jayachitra.kishor@sharda.ac.in.
Rashmi Priyadarshini (D) 81 SC P is an Associate Professor in Department of Electronics and Communication, Sharda University, Greater Noida, Uttar Pradesh, India. She completed her PhD degree from Sharda University. Her research interests are Wireless Sensor Network, Embedded systems and IoT. She has published many papers in reputed Journals and Conferences. She can be contacted at email: email: rashmi.priyadarshini@sharda.ac.in. 